\title{
VARIEDADES \\ ¿KARIMM O ȚARĪF? \\ (NOTAS SOBRE UN ESCULTOR ESCLAVO DE CALIFAS, A PROPÓSITO DE UNA PIEZA DEL MUSEO ARQUEOLÓGICO NACIONAL)
}

\author{
JUAN A. SOUTO * \\ Universidad Complutense. Madrid
}

En el Museo Arqueológico Nacional de Madrid se conserva un fragmento de mármol procedente de Córdoba, cubierto de decoración floral y con tres pequeños arcos ciegos de herradura ${ }^{~}$. Estos, a su vez, se «sostienen» mediante columnillas rematadas por cimacios (lámina I). A lo largo de los tres cimacios conservados - en origen hubo cuatro- puede leerse una inscripción árabe muy bien tallada en caracteres cúficos de relieve (figura 1).

En 1879, Amador de los Ríos hizo la siguiente lectura del textus receptus de la inscripción: كريم عبده..., que tradujo «... Karim, su siervo», frase que «parece aludir al artista que labró este fragmento» ${ }^{2}$. A

* El presente trabajo se inscribe en el proyecto de investigación «Epigrafia y construcción en al-Andalus omeya», subvencionado por la Fondation Max van Berchem (la Fondation Max van Berchem fue constituida en 1973 en homenaje a Max van Berchem (1863-1921), fundador de la epigrafía árabe como disciplina. Establecida en Ginebra, tiene como meta el promover el estudio de la arqueología, la historia, la geografía, la historia del arte, la epigrafía, la religión y la literatura árabes e islámicas). Los planteamientos generales de dicho proyecto figuran en Souto, J. A., "Epigraphy and building in Umayyad al-Andalus: genesis and prospects for a research project", en Vermeulen, U., \& De Smet, D., eds., Philosophy and Arts in the Islamic World. Proceedings of the Eighteenth Congress of the UEAI (Orientalia Lovaniensia Analecta, 87), Lovaina, 1998, 303-24. El autor desea agradecer los comentarios de su amigo y colega D. Alberto Montejo, quien le animó a elaborarlo; y las atenciones y facilidades concedidas por las Dras. Ángela Franco e Isabel Arias, del Museo Arqueológico Nacional, a la hora de hacer las tomas de datos de la pieza estudiada.

1 Su número de inventario es 50.369. Sus medidas en centímetros, las siguientes: altura: 47; longitud: 75 ; grosor: 15 . Su procedencia concreta es desconocida, aunque algunos autores la han atribuido al Alcázar omeya. D. Alberto Montejo, que en este momento estudia el edificio, me ha comunicado sus serias dudas al respecto. Esperamos la publicación de sus conclusiones.

${ }^{2}$ Amador de los Ríos y Villata, R., Inscripciones árabes de Córdoba precedidas de un estudio histórico-crítico de la Mezquita-Aljama, Madrid, 1879, 370.

Al-Qanțara XXVI, 1 (2005) 249-262 
continuación propuso las siguientes reconstrucción y traducción de un supuesto texto completo:

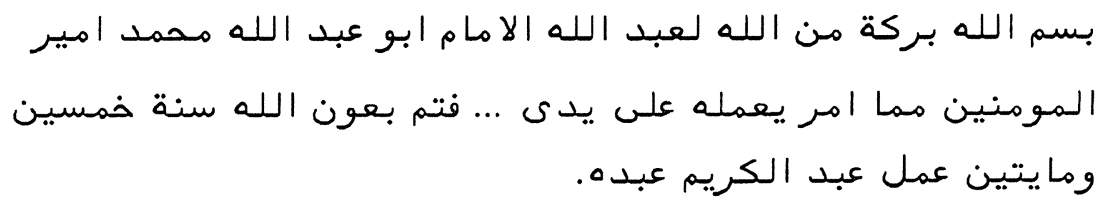

«En el nombre de Alláh. La bendición de Alláh para el siervo de Alláh el Imám Abú-Abdil-láh Mohámmad, Príncipe de los fieles. [Esto es] de lo que mandó hacer bajo la dirección de ... y se terminó con el auxilio de Alláh, el año cincuenta y doscientos ( 250 H. - 864 J. C.).- Obra de Abdul-Karim, su siervo» ${ }^{3}$.

La bibliografía dedicada desde entonces al fragmento en cuestión, una auténtica "pieza de museo», es amplia. De entre ella, y por orden cronológico, se destacan las siguientes referencias, a mi juicio las más importantes y significativas:

En 1932, Revilla editó el textus receptus كريم عبده, lo tradujo «Carim su siervo», se refirió a él como «inscripción alusiva al famoso Abdelcarim, encargado de obras por orden de Abderrahmán II» y fechó la pieza, implícitamente, en la época de ese emir (822-852) ${ }^{4}$.

En 1951, Gómez-Moreno se mostró algo escéptico tanto hacia la lectura como hacia las cronologías hasta entonces aceptadas: «[el nombre] puede corresponder a Abdelcarim, ministro de Abderrahman II, fallecido en 824. De ser así, tendríamos en este tablero el ejemplar decorativo más sobresaliente del siglo IX, dotado de un barroquismo singular; pero, aun con ello, no resulta verosímil alejarlo tanto de lo califal» ${ }^{5}$.

En 1957, Torres Balbás apuntó que el fragmento «tiene letreros en los cimacios de las columnas sobre las que arrancan los arcos de herradura. En ellos se lee la frase "Karim su siervo". Amador de los Ríos identificó, sin fundamento alguno, al tal Karim con un encargado de obras del emir Muhammad así llamado, y reconstruyó la ins-

3 Ídem, 374. He respetado los textos árabe y castellano y las transliteraciones de Amador de los Ríos. Éste, siempre escrupuloso y honrado, aportó sus razones para semejante reconstrucción, razones que discutiré más abajo.

${ }^{4}$ Revilla Vielva, R., Catálogo de las antigüedades que se conservan en el patio árabe del Museo Arqueológico Nacional, Madrid, 1932, n. ${ }^{\circ} 9$.

${ }^{5}$ Gómez-Moreno, M., El arte árabe español hasta los almohades. Arte mozárabe, Madrid, 1951, p. 180. 
cripción hasta con la fecha de 250 (864). Pero su estilo no difiere del califal del siglo siguiente» ${ }^{6}$.

En 1976, Stern señalaba que «sur la foi d'un nom, Abd al-Karim, gravé sur l'imposte de l'un des chapiteaux des colonnettes de cette pièce, M. Gómez-Moreno l'a attribuée à un ministre d'Abd ar-Rahman II, mort en 824. Il faut, à notre avis, la descendre aux dernières années d'Abd ar-Rahman III ou à al-Hakam II» 7 .

En 1991, Zozaya dijo de los cimacios que tienen una «inscripción de difícil lectura que se interpreta como "Karim su siervo"»; y del conjunto de la pieza, que «parece ser arte emiral aún, pero ya próximo a lo califal» ${ }^{8}$.

Vemos, pues, que este fragmento marmóreo ha sido objeto de discusión desde el punto de vista de su cronología. La lectura de su inscripción, sin embargo, no parece haber sembrado grandes dudas, aunque a mi juicio es incorrecta, a la vez que decisiva para fechar la obra con cierta precisión.

Volvamos al principio del asunto, es decir, a Amador de los Ríos, cuyas propuestas de texto y cronología se basaban en los siguientes puntos ${ }^{9}$ :

1. Sus propios conocimientos de los textos epigráficos constructivos omeyas andalusíes, casi todos ellos de época califal ${ }^{10}$.

2. Dos documentos de obras constructivas del emir Muhammad I (852-886): la inscripción de la puerta de San Esteban de la Mezquita Aljama de Córdoba, fechada en 241 / 22 mayo 855 - 9 mayo $856^{11}$; y la cita de Ibn 'Id̄ārī relativa a 250 / 13 febrero 864 - 1 febrero 865, donde se dice que ese emir completó la maqsūura de dicha mezquita e hizo numerosas construcciones en el Alcázar cordobés y sus almunias exteriores ${ }^{12}$.

${ }^{6}$ Torres Balbás, L., "Arte hispanomusulmán hasta la caída del califato de Córdoba", en Historia de España dirigida por Ramón Menéndez Pidal, V, Madrid, reed., 1982, 714.

7 Stern, H., Les mosaïques de la Grande Mosquée de Cordoue, Berlín, 1976, 27.

8 Zozaya, J., "Antigüedades andalusíes de los siglos VIII al XV. Salas XXX-XXXI", en VV.AA., Museo Arqueológico Nacional. Guia general, Madrid, 1991, II, 62-63, fielmente reproducido en una $2 .^{a}$ edición, 1996, vol. único, 196-97.

${ }^{9}$ Inscripciones árabes, 372-74.

${ }^{10}$ Véase el conjunto de su obra citada.

11 La publicación de referencia de esta inscripción es la de Ocaña Jiménez, M., "Inscripciones árabes fundacionales de la mezquita-catedral de Córdoba", Cuadernos de Madinat al-Zahrā', 2 (1988-90), n. 1 (= "Inscripciones árabes fundacionales").

${ }_{12}$ Ibn 'Id̄ārī, Al-Bayān al-mugrib fí ajbār al-Andalus wa-l-Magrib, vol. II, texto, ed. Colin y Lévi-Provençal, Leiden (1951), 98; trad. esp. en Souto, J. A., "El emirato de 
3. «Los caractéres artísticos que resplandecen en el venerado resto que estudiamos».

Todo esto lo llevó, como se ha visto, a insertar el nombre del emir Muhammad I y una fecha determinada (250 / 13 febrero 864 - 1 febrero 865 ) en un «texto-cliché». Hoy sus propuestas resultan inaceptables por varias razones:

1. El epíteto «Siervo de Dios» es propio de califas. Aplicado a un soberano andalusí tiene sus primeros precedentes epigráficos en 340 / 9 junio 951 - 28 mayo 952. Se refieren, por supuesto, a 'Abd al-Rahmān III (912-61, califa desde 929) ${ }^{13}$.

2. Lo mismo puede decirse acerca del título de «imán», que aparece con seguridad en la epigrafía constructiva andalusí en el texto fundacional del salón de 'Abd al-Rahmmān III en Madīnat al-Zahrā', fechado en $345 / 15$ abril 956 - 3 abril $957^{14}$.

3. «Emir de los Creyentes» es un título equivalente al de «califa». Ningún soberano omeya andalusí lo llevó antes de 'Abd al-Raḥmān III, que lo adoptó en 929, como es bien sabido. Aparece en la epigrafía constructiva omeya andalusí en muharram 318 / 3 febrero - 2 marzo 930, precisamente en la más antigua inscripción cali-

Muhammad I en el Bayān al-mugrib de Ibn 'Id̄ārī', Anaquel de Estudios Árabes, 6 (1995), § 19, donde se señalan los paralelos historiográficos del pasaje; véase también Idem, "Obras constructivas en al-Andalus durante el emirato de Muhammad I según el Bayan al-mugrib", Arqueología Medieval, 3 (1994), 29. Amador de los Ríos consideraba que la pieza podría proceder del Alcázar.

13 Capitel conservado en el Instituto de Valencia de Don Juan (Madrid): Gómez-Moreno, M., "Capiteles árabes documentados", Al-Andalus, VI (1941), 424-25 y fig. 15 (lectura); y capitel procedente de Loja (Granada), hoy perdido (?): Ocaña Jiménez, M., "Capiteles fechados del siglo X", Al-Andalus, V (1940), 439-40 y lám 7. Sobre este epíteto en las inscripciones omeyas andalusíes, véase Martínez Núñez, M. ${ }^{\mathrm{a}} \mathrm{A}$., "Sentido de la epigrafia omeya de al-Andalus", en Viguera Molins, M. ${ }^{a}$ J., y Castillo Castillo, C., coords., El esplendor de los Omeyas cordobeses. La civilización musulmana de Europa Occidental. Estudios, Granada, 2001, 415 (= «Sentido de la epigrafia»).

${ }^{14}$ Publicación de referencia: Martínez Núñez, M.a A., "La epigrafía del salón de 'Abd al-Rahmān III", en Vallejo Triano, A., coord., Madinat al-Zahrā'. El salón de 'Abd al-Rậmān III, Córdoba, 1995, n. 9 (= "La epigrafia del salón"). Su consigna en un epígrafe a nombre de Muhammad I (852-86) debe tomarse, en principio, con cautela, ya que no se trata de una pieza conservada, sino de un texto transmitido por un autor del siglo XI (Souto, J. A., "Un pasaje de al-'Uḍrī acerca de la [re]construcción de la muralla de Huesca en el año 261/874-875: observaciones y precisiones", en Vázquez de Benito, C., y Manzano Rodríguez, M. Á., eds., Actas XVI Congreso UEAI, Salamanca, 1995, 499-507). Lo mismo cabe decir acerca de su uso con referencia a los emires en las crónicas tardías. Sobre este título en las inscripciones omeyas andalusíes en general, véase "Sentido de la epigrafia", 415. 
fal conocida, que conmemora la [re]construcción de una azacaya en Écija (Sevilla) ${ }^{15}$.

4. El sintagma 'amal Fulān («obra de Fulano») aparece en la epigrafía constructiva andalusí en esa misma inscripción ${ }^{16}$.

5. Por lo que se refiere a ese tal 'Abd al-Karīm, no hay datos de nadie con ese nombre y «encargado de obras» del emir Muhammad I. Hay un 'Abd al-Karīm b. Mugit, destacado militar del alto emirato, fallecido en $825^{17}$, y un 'Abd al-Karīm b. Ilyās, de las gentes «notables y distinguidas» de la cora de Sidonia, que falleció en tiempos del emir 'Abd Allāh (888-912) ${ }^{18}$.

6. Formalmente, el fragmento del Museo Arqueológico Nacional carece de paralelos comparables fechados en el emirato de Muhammad I ${ }^{19}$, aunque sí los tiene posteriores ${ }^{20}$.

15 Publicación de referencia: Souto, J. A., "Las inscripciones árabes de la iglesia de Santa Cruz de Écija (Sevilla): dos documentos emblemáticos del Estado omeya andalusí", Al-Andalus-Magreb, 10 (2002-2003), inscripción n. ${ }^{\circ}{ }^{1}$. Sobre este título en las inscripciones omeyas andalusíes, véase "Sentido de la epigrafía", 415.

16 Véase la nota anterior. Esta cronología se corresponde con la de los primeros ejemplos orientales de obras firmadas: cf. Blair, S. S., y Bloom, J. M., "Signatures on Works of Islamic Art and Architecture", Damaszener Mitteilungen, 11 (1999), 51 y 55

${ }^{17}$ «Su mejor auxiliar [del emir al-Hakam I] es el nieto de un liberto, 'Abd al-Karim ben 'Abd al-Wahid ben Mugith, que ejerce las funciones de hachib durante la mayor parte del reinado. Este dignatario dirige la mayoría de las expediciones de castigo y de las ofensivas y ha de sobrevivir a su señor, para morir en la primavera de 825 (muharram 210), después de haber consagrado su existencia al servicio de la dinastía»: Lévi-Provençal, E., España musulmana hasta la caída del califato de Córdoba (711-1031 de J. C.), vol. IV de la Historia de España dirigida por Ramón Menéndez Pidal, Madrid, reed., $1982,120$.

18 Meouak, M., Pouvoir souverain, administration centrale et élites politiques dans l'Espagne umayyade (II $-I V^{e} / V I I I^{e}-X^{e}$ siècles), Helsinki, 1999, 166.

19 Sobre la decoración arquitectónica emiral, véase Cabañero Subiza, B., "Notas para el estudio de la evolución de los tableros parietales del arte andalusí desde la época del emirato hasta la de los reinos de taifas", Cuadernos de Madinat al-Zahrä', 4 (1999), 105-29, con bibliografia actualizada.

20 Véase Stern, Les mosaïques, esp. 27-28 (análisis comparativo de esta pieza) y, desde luego, los últimos avances en el conocimiento de la decoración floral del califato (me refiero fundamentalmente a Ewert, C., Die Dekorelemente der Wandfelder im Reichen Saal von Madinat az-Zahrä', Maguncia, 1996; Ídem, "Die Dekorelemente des spätumayadischen Fundkomplexes aus dem Cortijo del Alcaide (Prov. Córdoba)", $M a-$ drider Mitteilungen, 39 (1998), 356-532; e Ídem, "Westumayadische Kranzbäume, ihre Verbandten, ihre Vorfahren, ihr Nachleben", Damaszener Mitteilungen, 11 (1999), 95-122). 
Quedan, sin embargo, varias preguntas sin contestar. La primera es: ¿qué dice realmente la inscripción? Como puede verse en la lámina I y la figura 1, lo que queda de ella es claro:

$$
\text { | طر | يف ا عبده }
$$$$
\text { / Tar / if / 'abdihi }
$$

/ de Tar / if, / su siervo)

Amador de los Ríos y quienes lo siguieron directa o indirectamente confundieron $<\mathrm{t}>$ con $<\mathrm{k}>\mathrm{y}<\mathrm{f}>$ con $<\mathrm{m}>$, grafemas en verdad muy diferentes.

Mi reconstrucción se limita a suplir el texto del primero de los cuatro cimacios, el perdido. La inscripción completa sería la siguiente:

$$
\begin{aligned}
& \text { [عمل] | طر | يف اعبده / } \\
& \text { ['Amal] / Tar / if / 'abdihi }
\end{aligned}
$$

([Obra] / de Tar / if, / su siervo)

Aquí es donde surge la segunda pregunta: no se sabe nada de ningún 'Abd al-Karīm constructor, pero, ¿se puede saber quién era este Tarī? Creo que sí, siempre a base de documentación epigráfica andalusí coetánea. Veamos:

1. La firma de Tarïf figura, entre otras, en la cenefa del collarino de una pilastra del salón de 'Abd al-Raḥmān III en Madīnat al-Zahrā', del año 343 / 7 mayo 954 - 26 abril 955 (lámina II): 'Amal Gālib b. [Sa ']d wa-Sa 'ìd b. Fath wa-Tarîf al-yami`' 'abī[d...] («Obra de Gālib b. [Sa']d, Sa 'īd b. Fath y Tarîf, todos sierv[os de...]») ${ }^{21}$.

2. Tarif aparece, junto con Fath y Aflah, como firmante en otra cenefa de collarino de pilastra del mismo salón, fechable entre 342 y 345 / 18 mayo 953 - 3 abril 957, cronología del edificio, ya que no consta en la inscripción (lámina III): ['Amal] Fath wa-Aflaḥ wa-Ṭa[rïf («[Obra] de Fatḥ, Aflaḥ y Ṭa[rïf]») ${ }^{22}$.

21 "La epigrafía del salón", n. ${ }^{\circ} 7$.

22 Ídem, n. ${ }^{\circ}$ 5. Sobre Aflah y Fath: Souto, J. A., "Glyptographie omeyyade: signes lapidaires à la Grande Mosquée de Cordoue. Documentation de noms propres", Actes du XIIe Colloque International de Glyptographie de Saint-Christophe-en-Brionnais, Braine-le-Château (2001), 2.1 y 2.5, respectivamente (= "Documentation de noms propres"). Nuevos datos sobre Fath en Souto, "De gliptografia omeya: el nombre Fath en la Mezquita Aljama de Córdoba" Homenaje al Profesor Federico Corriente Córdoba (en prensa). 
3. TTarif firma a solas en una cartela de capitel de orden compuesto con idénticas procedencia y cronología que la pieza anterior. $\mathrm{Su}$ texto es igual al de la del Museo Arqueológico Nacional (figura 2): 'Amal Tar / if 'abdihi («Obra de Țar / if, su siervo») ${ }^{23}$.

4. Entre canecillos de sujección de la cornisa-imposta del interior del mihrāab de la Mezquita Aljama de Córdoba, fechado en $\underline{d} \bar{u}$ l-hiŷŷa 354 / 28 noviembre - 27 diciembre 965, aparecen las siguientes firmas: 'Amal Fath / wa-Tarîf (incipit, láminas IV y V: «Obra de Fath / y Tarīi»); 'Amal Nașr 'abdihi / 'Amal Badr 'abdihi (explicit: «Obra de Nașr, su siervo. / o; Obra de Badr, su siervo») ${ }^{24}$.

5. En el dorso del cierre de una arqueta de madera y plata dorada y nielada a nombre de Hišām II como heredero del califato está grabado 'Amal Badr wa TTarif / 'abidihi («Obra de Badr y Țarif, / sus siervos», en plural y no en dual, lámina VI) ${ }^{25}$. La obra, sin fecha, ha de situarse entre el 5 de febrero y el 1 de octubre de 976, lapso comprendido entre el nombramiento de Hišām como heredero y la muerte de su padre, el califa al-Ḥakam II.

Parece claro, entonces, que Tarīf era un tallista de calidad que trabajó en las principales obras de los primeros califas andalusíes, donde dejó inscrito su nombre, solo o junto con el de uno o más copartícipes.

¿Cuál era su cometido? es la siguiente pregunta, cuya respuesta viene sola: tallar o esculpir relieves e inscripciones, como es el caso ${ }^{26}$.

23 "La epigrafía del salón", n. ${ }^{\circ} 12$.

24 Publicación de referencia de la inscripción en que se integran: "Inscripciones árabes fundacionales", n. ${ }^{\circ}$. Las firmas en sí no están editadas, aunque sí reproducidas abundantemente en fotografias y comentadas en publicaciones relativas al edificio. Sobre Badr y Nașr: "Documentation de noms propres", 2.2 y 2.11 , respectivamente.

${ }_{25}$ Casamar, M., "Arqueta de Hišām II”, en Dodds, J. D., coord., Al-Andalus. Las artes islámicas en España, Madrid-N. York, 1992, n. ${ }^{\circ} 9$, con bibliografia.

${ }^{26} \mathrm{Mi}$ opinión acerca de esto está ya expresada en diversas publicaciones. Valgan como ejemplo dos de ellas, ambas de carácter introductorio y con bibliografia: "Los constructores de al-Andalus Omeya", en Castillo y Viguera, coords., El esplendor de los Omeyas cordobeses, 274-81, y "La construcción en al-Andalus omeya: las marcas de identidad de tallistas de piedra", en Pino, J. L. del, coord., Al-Andalus omeya, Córdoba, 2002, 105-18. Ahora bien, la naturaleza y circunstancias del último ejemplo presentado, la arqueta de madera y plata, parecen indicar que tanto Badr como Țarif, de ser los mismos documentados en Madīnat al-Zahrā' y la Mezquita Aljama de Córdoba, también trabajaron juntos en una obra casi «de orfebrería pura». Sobre el problema que plantea el que haya idénticos nombres a modo de firmas de obras contemporáneas pero de naturaleza dispar, véase "Documentation de noms propres", pásim, así como la bibliografía citada en esta misma nota. 
¿Cuál era su categoría? Muy alta, sin duda, respecto de su trabajo: la de 'abd («siervo» o «esclavo») del califa, lo cual no es poco ${ }^{27}$.

Por último, ¿puede todo esto ayudar a precisar la datación del fragmento del Museo Arqueológico Nacional? Evidentemente sí: su autoría por parte del Taríf escultor de piezas marmóreas permite situarla al menos entre 954 y 965, entre los califatos de 'Abd al-Raḥmān III (912-61, califa desde 929) y al-Ḥakam II (961-76), tal y como propuso Stern a partir del análisis de sus rasgos decorativos.

${ }^{27}$ Sobre el concepto de «esclavitud» y «esclavo» en este contexto, véase Puente, C. de la, "Entre la esclavitud y la libertad: consecuencias legales de la manumisión según el derecho mālikī", Al-Qanțara, XXI (2000), pp. 339-60. 


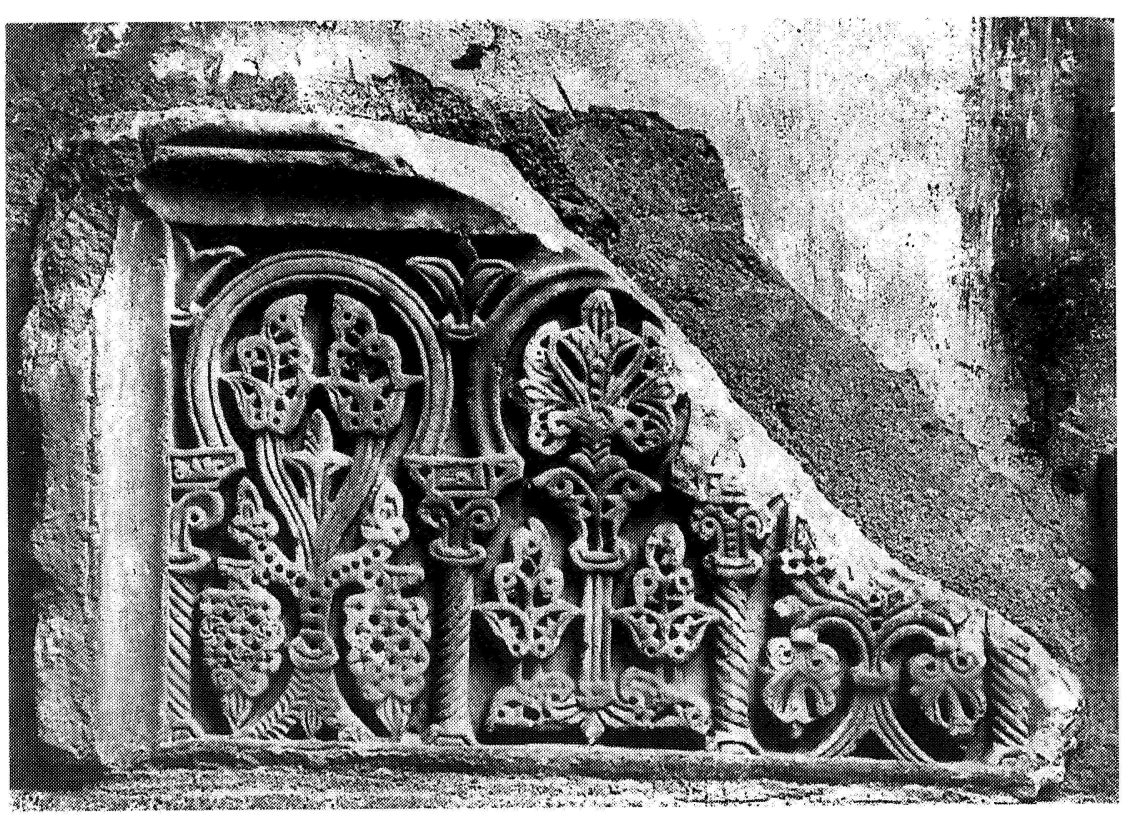

Lámina I. La pieza n. 50.369 del Museo Arqueológico Nacional (Stern, H., Les mosaïques de la Grande Mosquée de Cordoue, Berlín (1976), lámina 44 b). 


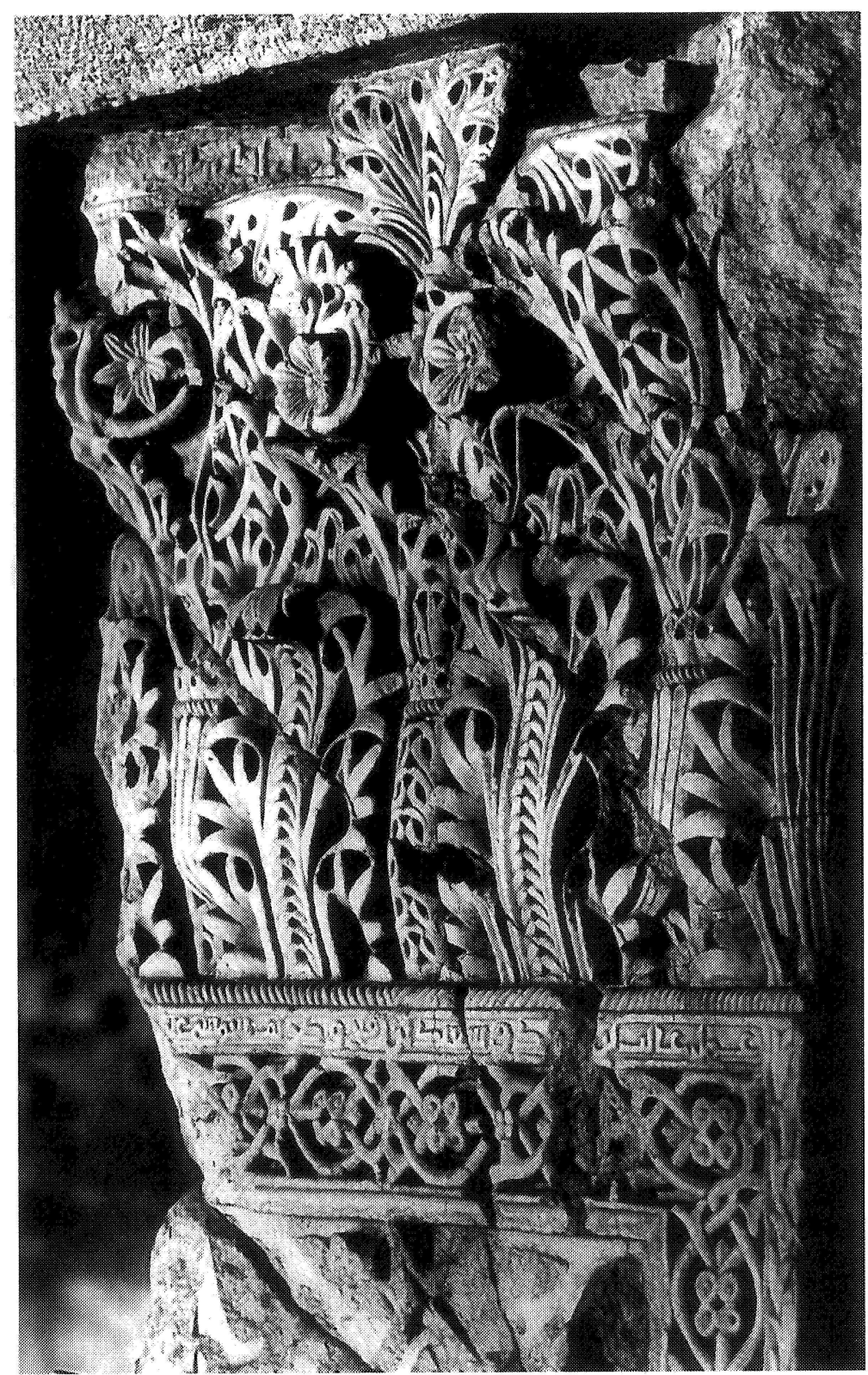

Lámina II. Capitel de una pilastra del salón de 'Abd al-Raḥmān III en Madīnat al-Zahrā', año 343 / 7 mayo 954 - 26 abril 955 (foto Instituto Arqueológico Alemán de Madrid, negativo R-140-67-6 - R. Friedrich). 


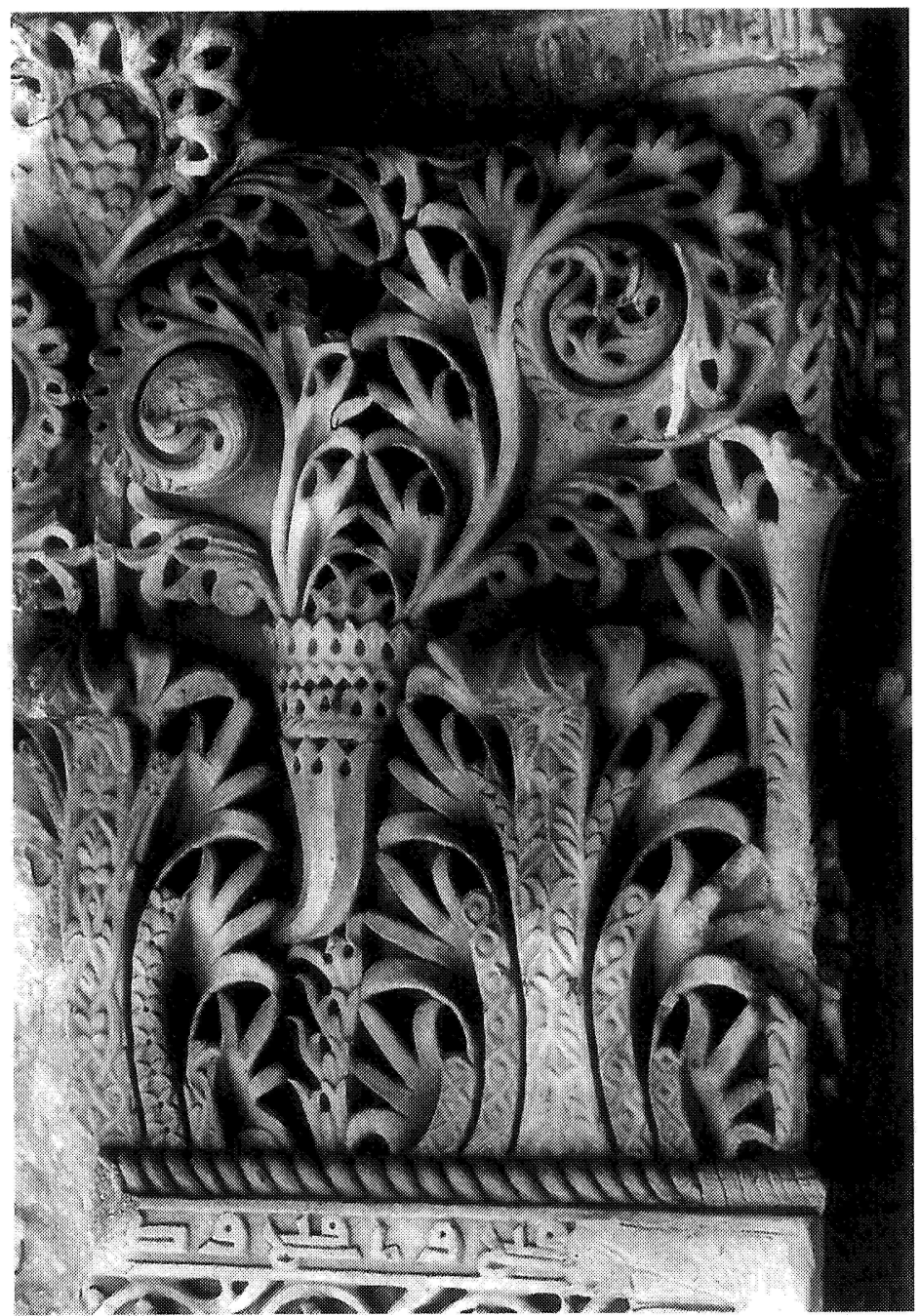

Lámina III. Capitel de otra pilastra del mismo salón, fechable entre 342 y 345 / 18 mayo 953 - 3 abril 957 (foto: Instituto Arqueológico Alemán de Madrid, negativo R-40-67-7 - R. Friedrich). 


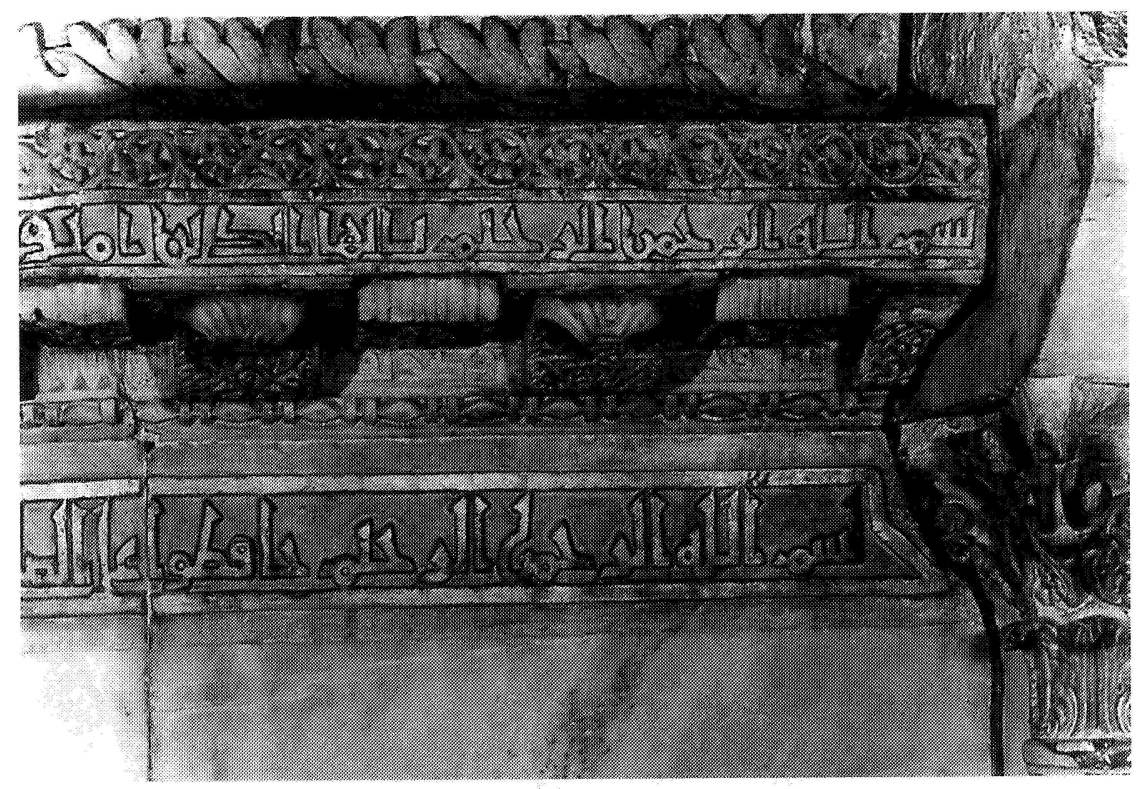

Lámina IV. Incipit de las inscripciones inferiores del interior del mihrab de la Mezquita Aljama de Córdoba (d 965), con las firmas de Fath y de Taríf entre canecillos de sujección (foto: Instituto Arqueológico Alemán de Madrid, negativo R-238-68-5 - P. Witte).

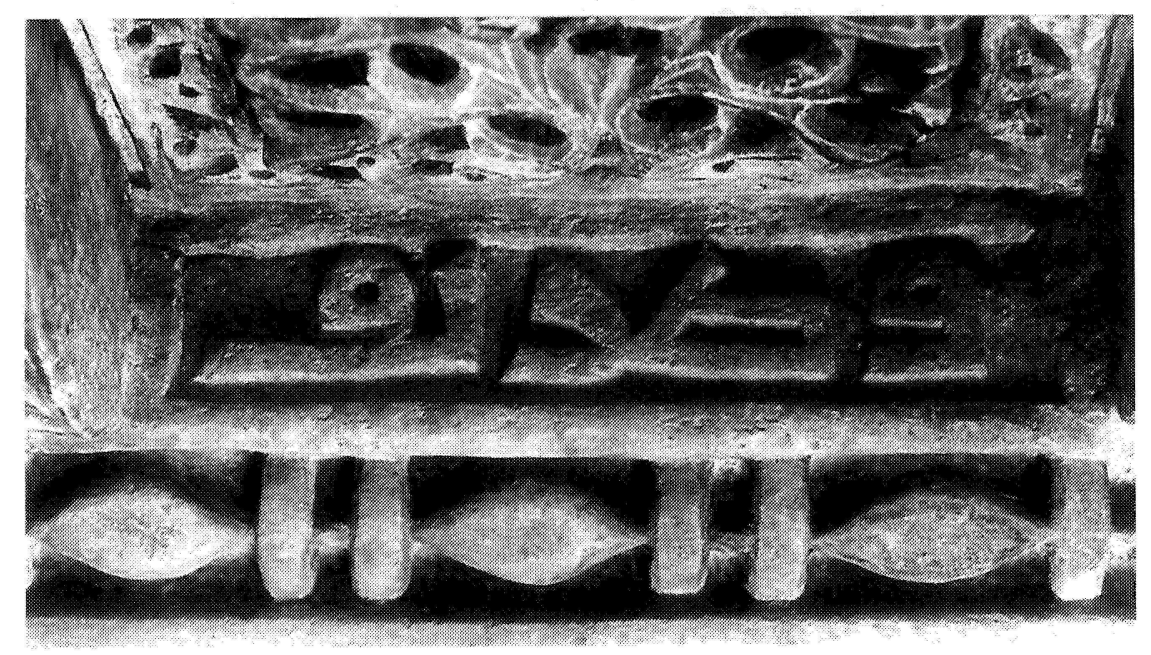

Lámina $V . \quad$ Detalle de la lámina anterior: wa Tarîf, «y Țarīf» (foto: Instituto Arqueológico Alemán de Madrid, negativo H-645). 


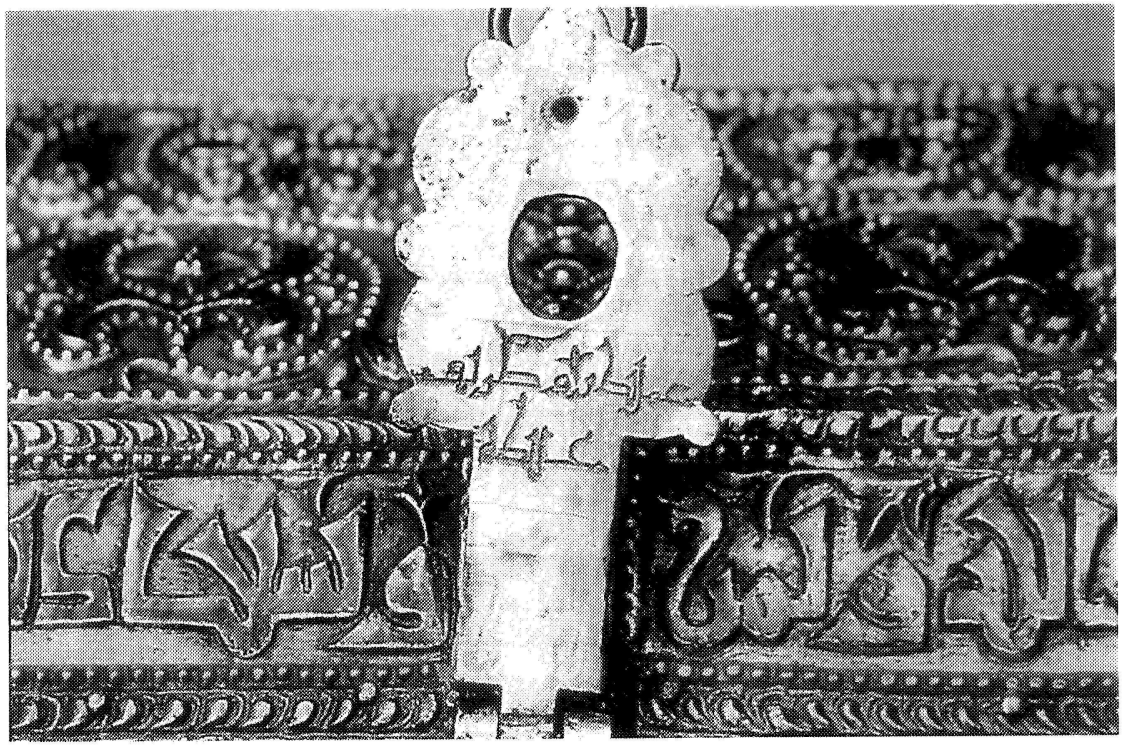

Lámina VI. Dorso del cierre de una arqueta a nombre de Hišām II como heredero del califato, período comprendido entre el 5 de febrero y el 1 de octubre de 976 (Blair, S. S., Islamic Inscriptions, Edimburgo (1998), figura 8.46). 

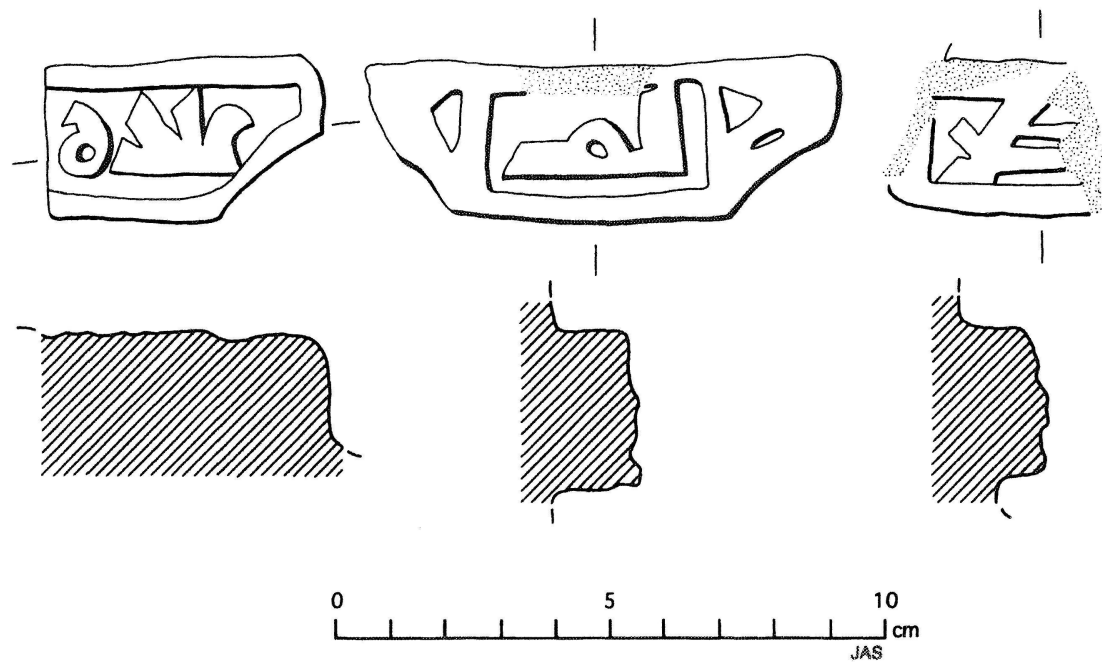

Figura 1. Inscripción en los cimacios de la pieza n. ${ }^{\circ} 50.369$ del Museo Arqueológico Nacional.
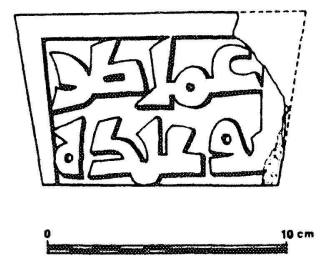

Figura 2. Cartela de capitel del salón de 'Abd al-Raḥmān III en Madinat al-Zahrā', fechable entre 342 y 345 / 18 mayo 953 - 3 abril 957 (Martínez Núñez, M. ${ }^{a}$ A., «La epigrafía del salón de 'Abd al-Raḥmān III», en Vallejo Triano, A., coord., Madinat al-Zahrā'. El salón de 'Abd al-Raḥmān III, Córdoba (1995), figura XI). 